\title{
Enhanced metabolism as a common feature of cancer plasticity
}

\author{
Minireview

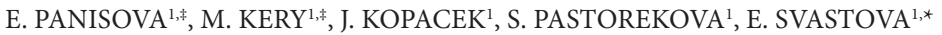 \\ ${ }^{1}$ Department of Molecular Medicine, Institute of Virology, Biomedical Research Center, Slovak Academy of Sciences \\ ${ }^{*}$ Correspondence: viruelis@savba.sk \\ ${ }^{*}$ Contributed equally to this work.
}

Received May 23, 2016 / Accepted June 15, 2016

\begin{abstract}
Cancer cells often rely on glycolytic metabolism in order to fulfill high demands of ATP and macromolecules for the sustained growth and proliferation. However, glycolysis is not necessarily the main source of energy for all cancer cells. Some of them rather depend on glutamine or lactate that favor the utilization of oxidative metabolic pathway. Different employment rate of metabolism creates variable products that participate in the formation of environmental milieu, which in turn triggers broad spectrum of cellular signaling pathways leading to migration, invasion, or proliferation. In this review we discuss different metabolic pathways promoted in tumor cells and describe the possibilities of their targeting as therapeutic strategies.
\end{abstract}

Key words: tumor metabolism, glycolysis, glutamine, lactate, reactive oxygen species (ROS), hypoxia inducible factor 1 $(H I F-1)$

\section{Tumor metabolism}

Metabolism is dynamically regulated system that accommodates cell's demands [1]. Tumor metabolism is still only partially understood due to its complexity caused by differences between tumor types and heterogeneity of cells belonging to tumor mass. These variances are further incurred by accumulation of random genetic mutations and enhanced by pericellular conditions $[2,3]$. Metabolic byproducts subsequently influence tumor microenvironment and can impact molecular or metabolic pathways of cells in paracrine or autocrine manner. Tumor cells are able to adapt to conditions of microenvironment and reprogram their metabolism according to their requirements.

\section{From hypoxia to aerobic glycolysis}

During the process of tumorigenesis, cells grow and proliferate regardless of extracellular signals $[4,5]$. Increased proliferation in pre-malignant lesions leads to gradual decline of oxygen $\left(\mathrm{O}_{2}\right)$ concentration with rising distance from the blood supply further supported by formation of an aberrant tumor vasculature. This results in considerable microenvironmental heterogeneity among cells within the proliferating tumor mass that enhances variability arisen from the genetic background of tumor cells. Emerging hypoxic regions form a niche, which selects for the cells capable of adapting to harsh conditions of microenvironment through the metabolic shift to anaerobic glycolysis. Constitutively upregulated glycolytic metabolism, which persists even in normoxic conditions (Warburg effect) confers cells a strong selective growth advantage during tumor progression and metastasis [6]. Another understanding of Warburg's observation is that glycolytic metabolism precedes hypoxia which thus does not represent the principal factor guiding the metabolic shift [1].

Glycolysis seems energetically ineffective compared to oxidative phosphorylation, creating only 2 molecules of adenosine triphosphate (ATP) per 1 molecule of glucose, whereas full glucose oxidation generates 38 ATP $[6,3]$. Although the glycolytic ATP production is very inefficient, under conditions of high glucose supply, it can outpace the ATP production from oxidative phosphorylation [7]. Secondly, oxidation of 
the product of glycolysis, pyruvate, requires its import into mitochondria, activation of highly regulated pyruvate dehydrogenase $(\mathrm{PDH})$ complex and is generally very slow. Pyruvate is therefore preferentially converted to lactic acid, which is in body fluids almost fully dissociated to lactate anion and proton [8]. In order to retain intracellular $\mathrm{pH}$ ( $\mathrm{pHi}$ ) neutral, protons $\left(\mathrm{H}^{+}\right)$have to be extruded from cell interior to extracellular space or neutralized by bicarbonate ions generated mostly by carbonic anhydrases [9]. Acidic extracellular $\mathrm{pH}$ (pHe) can subsequently become toxic to surrounding normal cells and support invasive and aggressive phenotype of cancer cells that are adapted and resistant to low $\mathrm{pH}$ environment $[6,10,3]$. Furthermore, acidic metabolites suppress functionality of and recognition by immune system [11], and can serve as mediators between cancer cells and cancer-associated stroma $[12,13$, 14]. Proliferating cells require huge amount of macromolecules that can be produced by biosynthetic reactions, which require carbon and reduced nicotinamide adenine dinucleotide phosphate (NADPH). Glucose itself and metabolic intermediates supply carbon and NADPH wherein pentose phosphate pathway (PPP) plays a significant role $[6,3,12]$. Moreover, glycolysis ensures ability to resist fluctuating changes in $\mathrm{O}_{2}$ concentration throughout stages of tumorigenesis [6].

It should also be noted that cancer cells employing aerobic glycolysis are not completely dependent on energy and substrates obtained from conversion of glucose through pyruvate to final product lactate, they rather partially convert pyruvate to acetyl coenzyme A (acetyl-CoA) that supplies cells with additional energy and precursors for anabolic reactions via the tricarboxylic acid (TCA) cycle $[15,16,17]$.

\section{Mediators of Warburg effect}

Hypoxia-inducible transcription factor HIF- $1 \alpha$ is considered as the master regulator of the glucose metabolism [18, 19]. Its stabilization by hypoxia or by potent oncogenic events (e.g. RAS mutation) leads to induction of glucose transporters (GLUT-1/3), key glycolytic enzymes (9 out of 10), lactate dehydrogenase (LDHA) involved in the conversion between pyruvate and lactate [20], and also to modulation of the TCA cycle performance through a pyruvate dehydrogenase kinase 1 (PDK1). PDK1-mediated phosphorylation of PDHA1, a component of the PDH complex responsible for oxidation of pyruvate to acetyl-coA, results in a decreased flux of the glucose-derived pyruvate to the TCA cycle, thus supporting the glycolysis itself [21].

Metabolic reprogramming is very often connected with deregulation of the oncogenic transcription factor c-Myc. c-Myc contributes to the Warburg effect by stimulation of the glucose transporter and LDHA expression [19] and is involved in the transcriptional cooperation with HIF-1 $\alpha$ that leads to induction of hexokinase HK2 and PDK1 [22].

In addition, wild-type p53 directly downregulates glucose transporters, and is also involved in inhibition of the initial glycolytic reactions. Thus, p53 mutation or deficiency, a prevalent feature of cancer cells, contribute to metabolic shift towards glycolysis [23].

\section{Advantages of oxidative metabolism}

The Warburg effect was initially explained by irreversible changes in mitochondria that render their oxidative metabolism non-functional [24]. However, it was later proven that most highly proliferative cancer cell lines do not have defects in oxidative metabolism $[25,4]$. In some circumstances, mitochondrial function is even crucial for transformation [26] and metabolism of several cancer cell lines, such as HeLa, is supported by oxidative phosphorylation [27].

Mitochondrial metabolism is a key constituent of cancer cell proliferation and growth generating ATP, reactive oxygen species (ROS), NADH, $\mathrm{FADH}_{2}$ and intermediates for macromolecular biosynthesis $[28,29,30]$. Indeed, the electron transport chain can function in the oxygen concentration as low as $0.5 \%[31]$.

The importance of oxidative metabolism in cancer cells, even with enhanced glycolysis, is supported by the role of $\mathrm{c}-\mathrm{Myc}$ in stimulation of the mitochondrial biogenesis. In addition to direct binding of c-Myc to promoters of genes involved in the mitochondrial structure and function, c-Myc upregulates key mitochondrial transcription factor A (TFAM) that regulates mitochondrial transcription and $\mathrm{mtDNA}$ replication [32]. Interestingly, HIF-1 controls mitochondrial function and increases $\mathrm{O}_{2}$ consumption in cells grown in hypoxia by switch of COX4 (cytochrome $c$ oxidase) subunits [33]. Expression of COX4I2 isoform is upregulated by HIF-1, which simultaneously activates transcription of the mitochondrial protease degrading COX4I1 isoform LON [34]. Under a reduced availability of oxygen, COX4I2 optimizes the efficiency of respiration and its downregulation in hypoxic conditions reduces the number of viable cells, decreases ATP level and increases ROS production [34]. Surprisingly, the master regulator of hypoxia HIF-1 keeps the activity of cytochrome $c$ oxidase, the terminal acceptor of $\mathrm{O}_{2}$ in electron transport chain, to boost the ATP production from respiration in conditions of reduced substrate availability.

\section{Glutamine and its versatility}

Glutamine rather than glucose constitutes an important energetic source that supports cell survival, growth and proliferation in some cancer cell types $[35,36,37,38]$. It represents the most abundant free amino acid in the body [39] and the main substrate for oxidation in the majority of transformed cells [40].

Upon entering cell cytoplasm by ASCT2 neutral amino acid transporter or SN2 transporters [36], glutamine is converted by glutaminase (GLS) to glutamate and ammonium that may cause changes in $\mathrm{pHi}$ and $\mathrm{pHe}$ values $[40,38,41]$. Released ammonia can function in acid resistance, which supports the role of glutamine in growth of cancer cells under acidic stress. 
It has been shown that cancer cells consume more glutamine in acidic $\mathrm{pH}$ and GLS1 isoforms KGA and GAC are active in the $\mathrm{pH}$ as low as 6.0 [42]. Increased ammonia production in cancer cells is also important for the activation of autophagy, the process of self-digestion in order to recycle macromolecules to promote cell survival in the case of starvation [43].

Glutamate is turned into $\alpha$-ketoglutarate $(\alpha-K G)$ by three enzymes - transaminases, 1 -amino acid oxidase, or glutamate dehydrogenase (GDH). Oxidation of $\alpha-K G$ by $\alpha-K G$ dehydrogenase to succinate supplies the classical TCA cycle thereby providing energy and metabolic intermediates as sources for cell building blocks exploitable in growth or proliferation [43]. Glutamine derived $\alpha-K G$ can also be involved in reductive carboxylation that leads to reverse production of citrate that is transported to cytoplasm and metabolized to acetyl-CoA and oxaloacetate important in lipid or amino acid synthesis $[44,43]$. The reductive carboxylation is favored in hypoxic conditions [45].

In the process of glutaminolysis, partial oxidation of glutamine to lactate, $\alpha-K G$ is converted within the TCA cycle from succinate to fumarate and malate that leaves mitochondria and is further metabolized to pyruvate and lactate. Despite producing $\mathrm{FADH}_{2}$ and $\mathrm{NADH}_{2}$, glutaminolysis supplies NADPH that plays a critical role in maintenance of the cellular antioxidant capacity by regenerating the pools of ROS scavengers glutathione (GSH) and thioredoxin (TRX). $\mathrm{NADPH}$ is further important for the synthesis of lipids and metabolism of nucleotides [30, 46, 41, 47, 38].

Besides its direct participation in oxidative metabolism, glutamine contributes to redox homeostasis by taking part in the formation of GSH, one of the most abundant antioxidants in mammalian cells [48]. GSH is a tripeptide of glutamate, cysteine and glycine. Except for glutamate itself being a part of GSH, intracellular glutamate pools are important for the activity of $\mathrm{X}_{c}^{-}$antiporter that exports glutamate and imports cysteine, another component of GSH [38]. The increased levels of GSH are important for resisting the oxidative stress associated with rapid metabolism and thereby support cell survival [4]. GSH is further involved in DNA repair, activation of transcription factors, cell cycle regulation, modulation of calcium homeostasis, or enzyme activity regulation [43].

As mentioned above, glutamine can regulate redox status by taking part in GSH formation. Glutamine, as a prominent stimulator of oxidative metabolism in cancer cells, further constitutes an important source of ROS production [49]. ROS-induced oxidative stress regulates several intracellular signaling pathways and processes including autophagy or apoptosis [50, 51].

Along with being the modulator of Warburg effect, c-Myc represents an important regulator of the glutamine metabolism. c-Myc activation causes glutamine addiction of glioma cells despite the presence of high amounts of glucose. This results in maintaining mitochondrial integrity and the TCA cycle function [36]. c-Myc directly induces the expression of glutamine transporters SLC7A5, or ASCT2 and is indi- rectly involved in the induction of the GLS1, a first enzyme of glutaminolysis, by repressing its negative regulators - miRNA23a and miRNA-23b [37].

\section{Lactate as a substrate for oxidation}

Lactate as a metabolic source initiating aerobic metabolism is beneficial for aggressive tumors as supported by the clinical observations of the positive association of elevated lactic acid levels with tumor progression, poor patient prognosis and overall survival $[52,53]$. In fact, the amount of lactate in tumors ranges from 4-40 $\mathrm{mM}$ with average of about $15 \mathrm{mM}$ compared to normal plasma concentrations $0.3-1.3 \mathrm{mM}[54,52,55]$.

Existing examples of lactate utilization in normal tissues including muscle and brain may provide insights into its potential functioning in cancer cells. In muscle tissue, white muscle fibers exposed to intensive exercise produce (by anaerobic glycolysis) and export excessive amounts of lactic acid, whereas slow twitching red muscle fibers can upload lactate and utilize it as a substrate for oxidative metabolism [56]. Another metabolic cooperation was observed in the brain between glial cells (more specifically astrocytes) and neurons, with astrocytes preferentially employing glycolysis and neurons having the preference for lactate oxidation [57, 58]. As mentioned earlier, these patterns of lactate shuttling between glycolytic and oxidative cells in normal tissues point to possible similar cooperation between cells in tumor mass. Sonveaux, et al. (2008) observed preferential lactate import in normoxia and its use to fuel the TCA cycle by oxidative $\mathrm{SiHa}$ cervical cancer cell line compared to glycolytic WiDr colorectal cells that favored glucose as a metabolic substrate. Estimated model of in vivo metabolic symbiosis proposed by authors is lactate production by glycolysis in hypoxic tumor regions, its diffusion to and exploitation by oxygenated cells for respiration thus saving glucose for cells in the hypoxic core in order to preserve and potentiate aggressive tumor phenotype (Figure 1) [59].

It should be mentioned that lactate has to be converted to pyruvate in order to enter the TCA cycle and stimulate oxidative metabolism.

\section{Elevated reactive oxygen species (ROS) as a hallmark of cancer}

One of many outcomes of oxidative metabolism is the production of ROS. Mitochondria represent the largest contributor to cellular ROS levels, with eight known sites that are capable of producing superoxide [60]. Another major sources of ROS are NADPH oxidases that are involved in diverse cellular phenomena in which ROS perform a control function. Low levels of ROS have beneficial effects on cell proliferation by stimulating the post-translational modifications of kinases and phosphatases [61], but their excessive production causes detrimental oxidative stress that leads to cell death [62]. 
Elevated ROS levels are believed to be a hallmark of cancer [63], thus raising the need to control their actions. Cancer cells adapt to detrimental effects of ROS by producing antioxidant molecules, such as TRX and GSH and link them with the reducing power of NAPDH [64]. NADPH production is therefore crucial for cancer cell survival also in the context of redox homeostasis and several metabolic pathways are involved in its production. Well documented pathways involve cytosolic conversion of the TCA cycle-derived malate and citrate to pyruvate and $\alpha-K G$, respectively, thus linking glutaminemediated supplementing of the TCA cycle to redox status maintenance. Third major source of NADPH comes from PPP that is also involved in the production of nucleotides for DNA synthesis [18].

Mitochondrial ROS are also tightly linked to the activation of hypoxia-response pathway. Recently, it was shown that the ROS-mediated oxidative stress leading to homodimerization of PHD2, as a result of disulfide bond formation, is linked to HIF-1 $\alpha$ accumulation [65]. Another hypothesis proposes indirect link between ROS and HIF- $1 \alpha$ - through the ROS-mediated upstream adjustments of the MAPK and PI3K signaling pathways, and possibly also of miRNA regulation [66]. Both of these growth factor-related pathways upregulate HIF-1a through actions of their downstream target mTORC1, a major metabolic regulator, while ERK kinase activates also the overall transcriptional activity of HIF-1 $\alpha$ via phosphorylation of its co-activator CBP/p300 [67]. mtROS-mediated upregulation of HIF- $1 \alpha$ is supported by additional observation that hypoxia induces microtubule-dependent transport of mitochondria to the perinuclear region with related induction of the HIF-1a transcriptional activity [68].

\section{Biosynthetic pathways that stimulate tumor growth and proliferation}

To allow for tumor cell proliferation, metabolic shift to the aerobic glycolysis has to be accompanied by elevated levels of subsidiary biosynthetic pathways. One part is represented by the cytosol-derived pathways, such as hexosamine biosynthetic pathway (HBP) or pentose phosphate pathway (PPP), that both stem from glycolysis. Second source of biosynthetic metabolites represent the TCA cycle-derived intermediates, as described below (Figure 2).

HBP consumes 2-5\% of imported glucose and metabolizes it to UDP- $N$-acetylglucosamine (UDP-GlcNAc), which is used as a donor for O-GlcNAcylation or N-glycosylation of myriad of proteins [69]. In HBP, fructose 6-phosphate is converted to glucosamine 6-phosphate (GlcN-6P) by glutamine-fructose6-phosphate aminotransferase (GFPT), while consuming glutamine. By subsequent series of reactions, HBP intermediates are linked to lipid (acetyl-CoA) and nucleotide (UDP) metabolisms [70]. Upregulation of HBP is documented in various cancer cell lines [71] and GFPT2, a rate-limiting enzyme of HBP, is also strongly induced in hypoxia $[72,73]$.

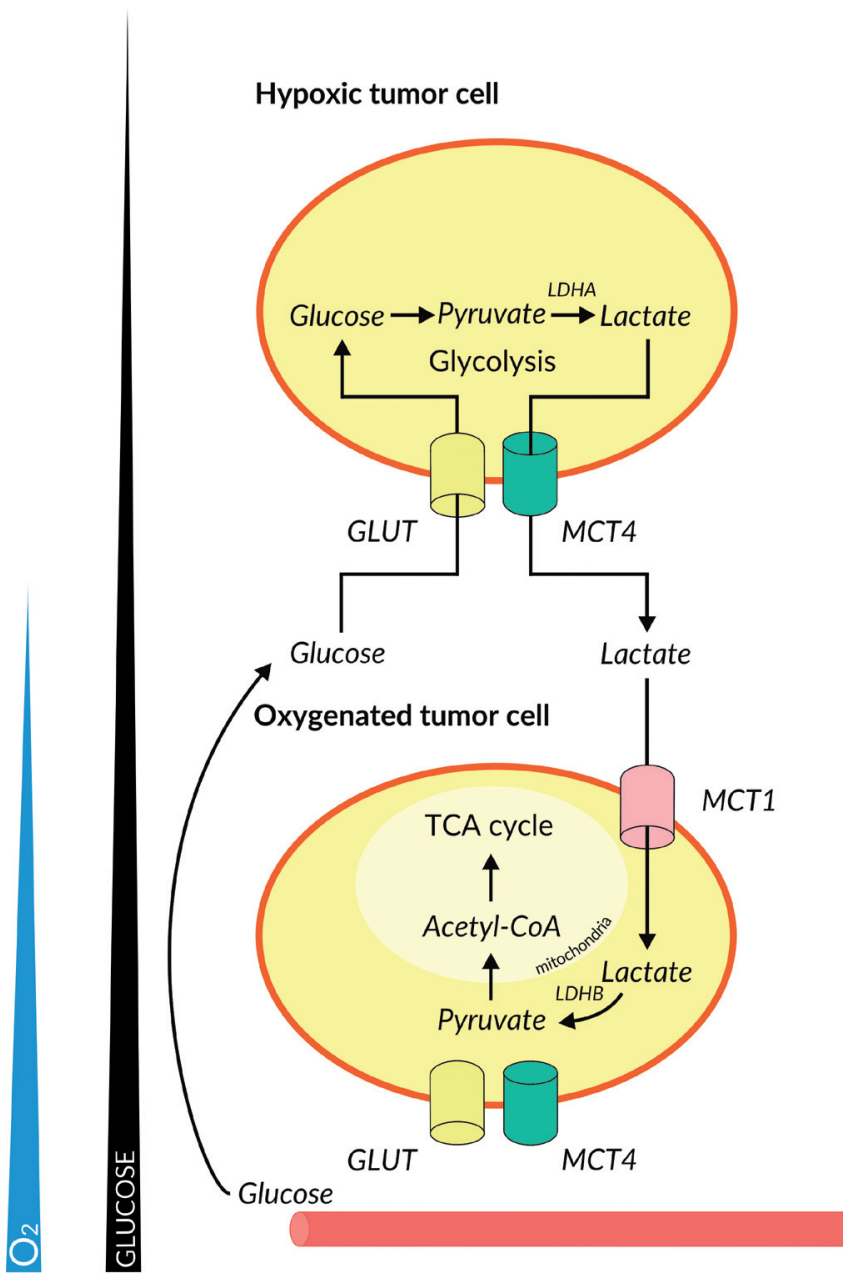

Figure 1. Estimated model of metabolic symbiosis in tumors. Hypoxic tumor cells prefer glycolytic use of glucose and convert it through pyruvate to the final product lactate by lactate dehydrogenase A (LDHA). Lactate is exported by MCT4 transporter to extracellular space, where it diffuses along its concentration gradient towards oxygenated tumor cells. Oxygenated cells preferentially import lactate by the major importer MCT1. Lactate is metabolized to pyruvate by lactate dehydrogenase B (LDHB), pyruvate enters mitochondria and is utilized in the TCA cycle for oxidative purpose. As a result, glucose can freely diffuse to distant regions containing hypoxic tumor cells and supply glycolysis. GLUT - glucose transporter, MCT - monocarboxylate transporter (adopted from the ref. 59).

Hypoxic pancreatic cancer cells that activate HBP pathway in a KRAS-dependent manner are therefore dependent on high glucose and glutamine supplies, important precursors that feed the HBP [72].

PPP consists of two mutually supportive pathways, an oxidative branch based on conversion of glucose-6-phosphate (G6P) through 3 irreversible reactions to ribulose-5phosphate while generating NADPH and the non-oxidative branch composed of several bidirectional reactions connecting ketose- and aldose-phosphates with additional glycolytic intermediates, such as fructose-6-phosphate (F6P) and 


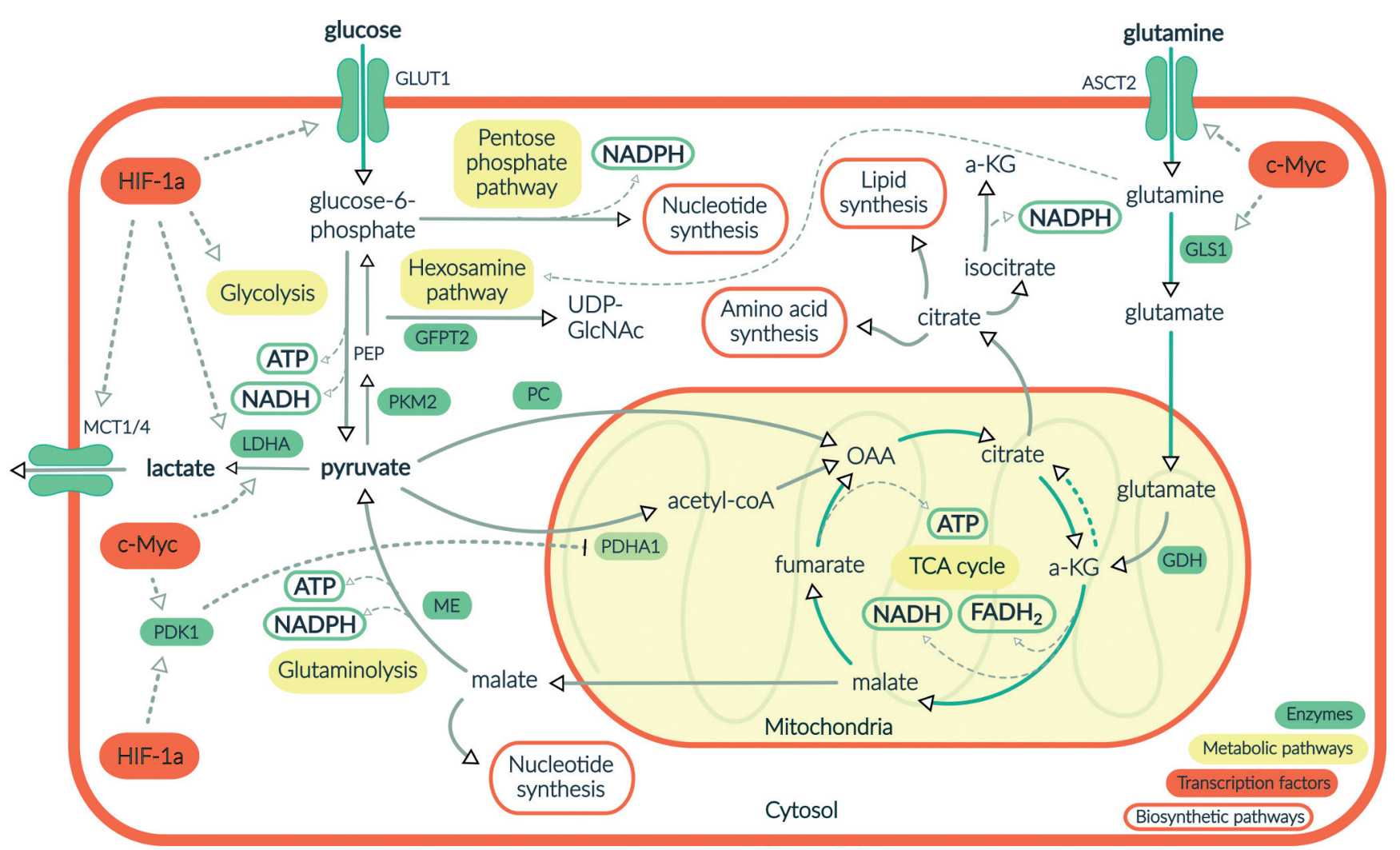

Extracellular space

Figure 2. Biosynthetic pathways involved in cancer metabolism. Hypoxic cancer cells rewire their metabolism towards aerobic glycolysis. Pyruvate is preferentially converted to lactate and glycolysis itself fuels several cytosol-derived biosynthetic pathways - such as pentose phosphate and hexosamine pathways, that produce important precursors for synthesis of nucleotides, amino acids and lipids. Hexosamine pathway also provides the precursor for glycosylation of proteins. TCA cycle represents additional hub for biosynthesis that can be replenished by extracellularly-derived glutamine. Several important enzymes involved in biosynthesis are regulated by HIF-1 $\alpha$ and c-Myc transcription factors. They upregulate enzymes engaged in glycolysis, downregulate mitochondrial activity through inhibiting PDHA and c-Myc is also a major regulator of glutamine metabolism. Oxidative branch of PPP and several reactions, such as conversion of malate to pyruvate and conversion of isocitrate to $\alpha$-KG also produce NAPDH. With glycolysis-derived ATP and $\mathrm{NADH}$, they can be used to fuel aforementioned biosynthetic pathways.

a-KG - alfa-ketoglutarate, PEP - phosphoenolpyruvate, UDP-GlcNAc - Uridine diphosphate $N$-acetylglucosamine, ASCT2 - ASC amino-acid transporter 2, GDH - glutamate dehydrogenase, GFPT2 - Glutamine fructose-6-phosphate aminotransferase 2, GLS1 - Glutaminase, GLUT1 - Glucose transporter 1, LDHA - Lactate dehydrogenase A, MCT1/4 - Monocarboxylate transporters 1/4, ME - Malate dehydrogenase, PC - Pyruvate carboxylase, PDHA - Pyruvate dehydrogenase E1 component subunit alpha, PDK1 - Pyruvate dehydrogenase kinase, PKM2 - Pyruvate kinase isozyme M2

glyceraldehyde-3-phosphate (G3P) [74]. Enzymes involved in PPP, that are frequently deregulated in cancer, are subjected to allosteric regulation by their products or other metabolites, thus allowing flexible metabolic response to diverse stimuli [75]. Glucose-6-phosphate dehydrogenase (G6PDH), a rate-limiting enzyme in the oxidative branch responsible for diverting the G6P into PPP is also activated by several signaling pathways, involving PI3K, RAS or SRC $[76,77,78]$ whereas its negative regulation is under the control of the low $\mathrm{NAD}+/ \mathrm{NADPH}$ ratio. Key enzymes in the non-oxidative branch, transketolase (TKT) and transaldolase (TALDO) are also overexpressed in various cancers $[79,80]$ and in rapidly growing cancer cells generate the majority of ribonucleotides used in the DNA synthesis [81]. Additional control of the glucose flux through glycolysis, HBP and PPP is dependent on the M2 isoform of pyruvate kinase (PKM2), a rate-limiting enzyme of the last glycolytic step - the conversion of phosphoenol pyruvate (PEP) to pyruvate [82]. Tumor associated expression of PKM2 with lowered enzymatic activity provides metabolic advantage via accumulation of upstream glycolytic intermediates capable of feeding the PPP [83, 84, 23, 64].

NADPH produced in the PPP serves as one of the most important sources of reducing power that feeds the glutathione-mediated antioxidant reactions, through ROS scavenging. It was demonstrated, that PPP derived NADPH counteracts the ROS-induced anoikis upon cell detachment [85]. NADPH produced in PPP is also linked to DNA and lipid synthesis [86].

As described above, second major branch of the biosynthetic pathways stems from the TCA cycle, because many basic 
precursors for synthesis of amino acids, lipids and nucleotides derive from the TCA cycle intermediates [4]. Shunted TCA cycle intermediates create a truncated cycle that needs to be replenished. There are several ways how to supplement the TCA cycle. In some context, cells can enhance the activity of pyruvate carboxylase (PC) that is involved in converting the pyruvate directly to oxalacetate, a TCA cycle intermediate, or in other context, glutamine can serve as a potent precursor for the TCA cycle intermediates [87].

\section{Therapy based on targeting tumor metabolism}

Metabolism of cancer cells is often not dedicated to a single branch, but is rather intermediary, thus mirroring the metabolic adaptability of cells based on the availability of resources as well as the ability to cooperate in order to preserve and potentiate aggressive tumor phenotype. Accordingly, tumor cells dispose compensatory mechanisms upregulating glycolysis or mitochondrial metabolism when one of these metabolic pathways is suppressed. This constitutes an obstacle for cancer therapies targeting a single branch of metabolism. Therapeutic targets emerging as potentially suitable for inhibition of mitochondrial metabolism include poorly perfused tumors with limited glucose availability but sufficient amount of oxygen to sustain ATP generation; tumors highly addicted to mitochondrial metabolism lacking the ability of glycolytic compensation; and tumors exploiting both glycolysis and oxidative metabolism [30].

Several steps of glycolysis have been shown promising as therapeutic targets. Phloretin, that targets glucose transport across plasma membrane, inhibited tumor xenograft growth in vivo [88]. The therapies employing two inhibitors of enzyme hexokinase (catalyzing initial step of glycolysis) lonidamine and 2-deoxyglucose have been tested in clinical trials in several different solid tumors $[89,90]$. TLN-232 suppresses pyruvate kinase that converts phosphoenolpyruvate into the product of glycolysis pyruvate and its effects have been studied in clinical trials with metastatic melanoma and renal cell carcinoma [91]. The reduction of pyruvate to lactate is regulated by enzymes including LDHA, which catalyses the formation of lactate from pyruvate, and PDK1 that blocks activity of $\mathrm{PDH}$ responsible for conversion of pyruvate to acetyl-CoA. Knocking down LDHA or inhibiting PDK1 by dichloroacetate (DCA) has been shown to reduce proliferation of cancer cells in vitro, with DCA being able to reduce the number of lung metastases of 13762 MAT cells injected into the tail vein of rats $[92,93]$.

As mentioned above, glutamine is a crucial amino acid important for ATP generation, macromolecule biosynthesis, or production of NADPH [30]. Many cancer cells are glutamine addicted and therefore targeting its metabolism is of a great interest in cancer therapy designs [40]. Compound 968 [94] and bis-2-(5-phenylacetamido-1,2,4-thiadiazol2-yl)ethyl sulphide (BPTES) [95] are inhibitors of GLS (an enzyme converting glutamine to glutamate). Compound 968 has been shown to delay the growth of lymphoma xenografts expressing GLS [94]. BPTES impaired the growth of P493 lymphoma-derived xenografts [95]. The conversion of glutamate to $\alpha-K G$ can be inhibited by aminooxyacetate (AOA) that targets transaminases; or epigallocatechin gallate (EGCG) that suppresses GDH. AOA was efficient in reducing tumor growth in mice with breast adenocarcinoma xenografts and autochtonous neuroblastomas [96, 97]; the use of EGCG, a green tea polyphenol, suppressed the growth of neuroblastoma xenografts $[98,96,41]$.

Metformin belongs to one of the most potential drugs selectively targeting metabolism of cancer cells. It lowers blood glucose and circulating insulin levels in diabetic patients [99]. Mechanisms of metformin mediated inhibition of cancer cell growth include reduction of circulating levels of mitogen insulin that upon binding to insulin growth factor receptor stimulates protumorigenic signaling pathways [100]. Second possible mechanism is inhibition of electron transport chain I leading to the decrease of ATP production in cells expressing organic cation transporter (OCTs) required for metformin import [30]. The combination of metformin with conventional therapies is currently evaluated in a number of clinical trials [101]. Other compounds inhibiting mitochondrial ATP production involve VLX600 [102], or gamitrinib [103]. The list of inhibitors of different metabolic pathways is reviewed in Tennant et al., 2010 [91].

It is important to mention that monotherapies could result in compensatory mechanisms and therefore, simultaneous targeting of different metabolic branches constitutes a promising strategy for cancer treatment.

\section{Conclusion}

To survive and progress, tumor cells need to adapt to ever changing conditions of tumor microenvironment. On the other hand, the constitution of tumor microenvironment is highly affected by products of cancer cell metabolism. Due to different tissue origins, metabolism among many cancer types is considerably heterogenous. Even a single tumor represents a diverse conglomeration of metabolic phenotypes as a result of increased metabolic plasticity compared to normal tissues. Tumor cells reprogram internal oncogenic signaling to converge and alter intrinsic metabolic pathways. Apparently, cancer cells need to establish rapid ATP generation for energy demands, increased biosynthesis of macromolecules and tightened maintenance of appropriate cellular redox status. Concurrent targeting of several steps of metabolic pathways therefore represents a promising therapeutic strategy to reduce cancer cell survival.

Acknowledgements: This work was supported by following grants: Research and Development Support Agency (APVV-14-0816), Slovak Scientific Grant Agency (VEGA 2/0155/15, VEGA 2/0147/15), and Bilateral Scientific Cooperation between the Slovak Academy of Sciences and The Ministry of Science and Technology, Taiwan (SAS-MOST-JRP-2014/10). 


\section{References}

[1] VANDER HEIDEN MG, CANTLEY LC, THOMPSON CB Understanding the Warburg effect: the metabolic requirements of cell proliferation. Science 2009; 324: 1029-1033. http://dx.doi.org/10.1126/science.1160809

[2] MORITA T, NAGAKI T, FUKUDA I, OKUMURA K Clastogenicity of low $\mathrm{pH}$ to various cultured mammalian cells. Mutat Res 1992;268:297-305.http://dx.doi.org/10.1016/00275107(92)90235-T

[3] FANG JS, GILLIES RD, GATENBY RA Adaptation to hypoxia and acidosis incarcinogenesis and tumor progression. Semin Cancer Biol 2008; 18: 330-337. http://dx.doi. org/10.1016/j.semcancer.2008.03.011

[4] DEBERARDINIS RJ Is cancer a disease of abnormal cellular metabolism? New angles on an old idea. Genet Med 2008; 10: 767-777. http://dx.doi.org/10.1097/GIM.0b013e31818b0d9b

[5] HANAHAN D, WEINBERG RA Hallmarks of caner: the next generation. Cell 2011; 144: 646-674. http://dx.doi. org/10.1016/j.cell.2011.02.013

[6] GATENBY RA, GILLIES RJ Why do cancers have high aerobic glycolysis? Nat Rev Cancer 2004; 4: 891-899. http:// dx.doi.org/10.1038/nrc1478

[7] GUPPY M, GREINER E, BRAND K The role of the Crabtree effect and an endogenous fuel in the energy metabolism of resting and proliferating thymocytes. European Journal of Biochemistry 1993; 212: 95-99. http://dx.doi.org/10.1111/ j.1432-1033.1993.tb17637.x

[8] CURI R, NEWSHOLME P, NEWSHOLME EA Metabolism of pyruvate by isolated rat mesenteric lymphocytes, lymphocyte mitochondria and isolated mouse macrophages. The Biochemical journal 1988; 250: 383-388. http://dx.doi. org/10.1042/bj2500383

[9] ONDRISKOVA E, DEBREOVA M, PASTOREKOVA S Tumor-associated carbonic anhydrases IX and XII. In: Supuran CT, De Simone G, editors. Carbonic anhydrases as biocatalysts. Elsevier, 2015: 169-205.

[10] SWIETACH P, VAUGHAN-JONES RD, HARRIS AL Regulation of tumor $\mathrm{pH}$ and the role of carbonic anhydrase 9. Cancer Metastasis Rev 2007; 26: 299-310. http://dx.doi. org/10.1007/s10555-007-9064-0

[11] FISCHER K, HOFFMANN P, VOELKL S, MEIDENBAUER $\mathrm{N}$, AMMER J et al. Inhibitory effect of tumor cell-derived lactic acid on human T cells. Blood 2007; 109: 3812-3819. http://dx.doi.org/10.1182/blood-2006-07-035972

[12] KROEMER G, POUYSSEGUR J Tumor cell metabolism: Cancer's Achilles' heel. Cancer Cell 2008; 13: 472-482. http:// dx.doi.org/10.1016/j.ccr.2008.05.005

[13] FIASCHI T, MARINI A, GIANNONI E, TADDEI ML, GANDELLINI $P$ et al. Reciprocal metabolic reprogramming through lactate shuttle coordinately influences tumor-stroma interplay. Cancer Res 2012; 72: 5130-5140. http://dx.doi. org/10.1158/0008-5472.CAN-12-1949

[14] RATTIGAN YI, PATEL BB, ACKERSTAFF E, SUKENICK G, KOUTCHER JA et al. Lactate is a mediator of metabolic cooperation between stromal carcinoma associated fibroblasts and glycolytic tumor cells in the tumor microenvironment.
Exp Cell Res 2012; 318: 326-335. http://dx.doi.org/10.1016/j. yexcr.2011.11.014

[15] BRAND K Glutamine and glucose metabolism during thymocyte proliferation. Pathways of glutamine and glutamate metabolism. Biochem J 1985; 228: 353-361. http://dx.doi. org/10.1042/bj2280353

[16] FORBES NS, MEADOWS AL, CLARK DS, BLANCH HW Estradiol stimulates the biosynthetic pathways of breast cancer cells: detection by metabolic flux analysis. Metab Eng 2006; 8: 639-652. http://dx.doi.org/10.1016/j.ymben.2006.06.005

[17] DEBERARDINIS RJ, MANCUSO A, DAIKHIN E, NISSIM I, YUDKOFF $M$ et al. Beyond aerobic glycolysis: transformed cells can engage in glutamine metabolism that exceeds the requirement for protein and nucleotide synthesis. Proc Natl Acad Sci U S A 2007; 104: 19345-19350. http://dx.doi. org/10.1073/pnas.0709747104

[18] LEVINE AJ, PUZIO-KUTER AM The control of the metabolic switch in cancers by oncogenes and tumor suppressor genes. Science 2010; 330: 1340-1344. http://dx.doi. org/10.1126/science.1193494

[19] KOPPENOL WH, BOUNDS PL, DANG CV Otto Warburg's contributions to current concepts of cancer metabolism. Nat Rev Cancer 2011; 11: 325-337. http://dx.doi.org/10.1038/ $\underline{\operatorname{nrc} 3038}$

[20] LEE JW, BAE SH, JEONG JW, KIM SH, KIM KW Hypoxiainducible factor (HIF-1)alpha: its protein stability and biological functions. Exp Mol Med 2004; 36: 1-12. http:// dx.doi.org/10.1038/emm.2004.1

[21] KIM JW, TCHERNYSHYOV I, SEMENZA GL, DANG CV HIF-1-mediated expression of pyruvate dehydrogenase kinase: a metabolic switch required for cellular adaptation to hypoxia. Cell Metab 2006; 3: 177-185. http://dx.doi. org/10.1016/j.cmet.2006.02.002

[22] DANG CV, KIM JW, GAO P, YUSTEIN J The interplay between MYC and HIF in cancer. Nat Rev Cancer 2008; 8: 51-56. http://dx.doi.org/10.1038/nrc2274

[23] ZHENG J Energy metabolism of cancer: Glycolysis versus oxidative phosphorylation (Review). Oncol Lett 2012; 4: 1151-1157. http://dx.doi.org/10.3892/ol.2012.928

[24] WARBURG O On the origin of cancer cells. Science 1956; 123 : 309-314. http://dx.doi.org/10.1126/science.123.3191.309

[25] MORENO-SANCHEZ R, RODRIGUEZ-ENRIQUEZ S, MARIN-HERNANDEZ A, SAAVEDRA E Energy metabolism in tumor cells. The FEBS journal 2007; 274: 1393-1418. http://dx.doi.org/10.1111/j.1742-4658.2007.05686.x

[26] FUNES JM, QUINTERO M, HENDERSON S, MARTINEZ D, QURESHI U et al. Transformation of human mesenchymal stem cells increases their dependency on oxidative phosphorylation for energy production. PNAS 2007; 104: 6223-6228. http://dx.doi.org/10.1073/pnas.0700690104

[27] HERST PM, BERRIDGE MV Cell surface oxygen consumption: a major contributor to cellular oxygen consumption in glycolytic cancer cell lines. Biochimica et biophysica acta 2007; 1767: 170-177.

[28] WEINBERG F, HAMANAKA R, WHEATON WW, WEINBERG S, JOSEPH J ET AL Mitochondrial metabolism and ROS generation are essential for Kras-mediated tumorigenic- 
ity. Proc Natl Acad Sci USA 2010; 107: 8788-8793 . http:// dx.doi.org/10.1073/pnas.1003428107

[29] FOGAL V, RICHARDSON AD, KARMALI PP, SCHEFFLER IE, SMITH JW et al. Mitochondrial p32 protein is a critical regulator of tumor metabolism via maintenance of oxidative phosphorylation. Mol Cell Biol 2010; 30: 1303-1318. http:// dx.doi.org/10.1128/MCB.01101-09

[30] WEINBERG SE, CHANDEL NS Targeting mitochondria metabolism for cancer therapy. Nat Chem Biol, 2015; 11: 9-15. http://dx.doi.org/10.1038/nchembio.1712

[31] RUMSEY WL, SCHLOSSER C, NUUTINEN EM, ROBIOLIO M, WILSON DF Cellular energetics and the oxygen dependence of respiration in cardiac myocytes isolated from adult rat. J Biol Chem 1990; 265, 15392-15402.

[32] LI F, WANG Y, ZELLER KI, POTTER JJ, WONSEY DR et al. Myc stimulates nuclearly encoded mitochondrial genes and mitochondrial biogenesis. Mol Cell Biol 2005; 25: 6225-6234. http://dx.doi.org/10.1128/MCB.25.14.6225-6234.2005

[33] DENKO NC. Hypoxia, HIF1 and glucose metabolism in the solid tumour. Nat Rev Cancer 2008; 8: 705-713. http://dx.doi. org/10.1038/nrc2468

[34] FUKUDA R, ZHANG H, KIM JW, SHIMODA L, DANG $\mathrm{CV}$ et al. HIF-1 regulates cytochrome oxidase subunits to optimize efficiency of respiration in hypoxic cells. Cell 2007; 129: 111-122. http://dx.doi.org/10.1016/j.cell.2007.01.047

[35] REITZER LJ, WICE BM, KENNELL D Evidence that glutamine, not sugar, is the major energy source for cultured HeLa cells. J Biol Chem 1979; 254: 2669-2676.

[36] WISE DR, DEBERARDINIS RJ, MANCUSO A, SAYED N, ZHANG XY et al. Myc regulates a transcriptional program that stimulates mitochondrial glutaminolysis and leads to glutamine addiction. Proc Natl Acad Sci USA 2008; 105: 18782-18787. http://dx.doi.org/10.1073/pnas.0810199105

[37] GAO P, TCHERNYSHYOV I, CHANG, TC, LEE YS, KITA K et al. c-Myc suppression of miR-23a/b enhances mitochondrial glutaminase expression and glutamine metabolism. Nature 2009; 458: 762-765. http://dx.doi.org/10.1038/nature07823

[38] DEBERARDINIS RJ, CHENG T Q's next: the diverse functions of glutamine in metabolism, cell biology and cancer. Oncogene 2010; 29: 313-324. http://dx.doi.org/10.1038/ onc. 2009.358

[39] BERGSTROM J, FURST P, NOREE LO, VINNARS E Intracellular free amino acid concentration in human muscle tissue. J Appl Physiol 1974; 36, 693-699.

[40] SOUBA WW Glutamine and cancer. Ann Surg 1993; 218 : 715-728. http://dx.doi.org/10.1097/00000658-199312000$\underline{00004}$

[41] HENSLEY CT, WASTI AT, DEBERARDINIS RJ Glutamine and cancer: cell biology, physiology, and clinical opportunities. J Clin Invest 2013; 123, 3678-3684. http://dx.doi.org/10.1172/ JCI69600

[42] HUANG W, CHOI W, CHEN Y, ZHANG Q, DENG H et al. A proposed role for glutamine in cancer cell growth though acid resistance. Cell Research 2013; 23: 724-727. http://dx.doi. org/10.1038/cr.2013.15

[43] MICHALAK KP, MACKOWSKA-KEDZIORA A, SOBOLEWSKI B, WOZNIAK P Key roles of glutamine pathways in reprogramming the cancer metabolism. Oxid Med Cell Longev 2015; 2015: 964321.

[44] MULLEN AR, WHEATON WW, JIN ES, CHEN PH, SULLIVAN LB et al. Reductive carboxylation supports growth in tumour cells with defective mitochondria. Nature 2012; 481 : 385-388.

[45] METALLO CM, GAMEIRO PA, BELL EL, MATTAINI KR, YANG J et al. Reductive glutamine metabolism by IDH1 mediates lipogenesis under hypoxia. Nature 2011; 481: 380-384.

[46] Ahn CS, Metallo CM Mitochondria as biosynthetis factories for cancer proliferation. Cancer Metab 2015; 3:1. http://dx.doi. org/10.1186/s40170-015-0128-2

[47] MARTINEZ-REYES I, CHANDEL NS Mitochondrial one-carbon metabolism maintains redox balance during hypoxia. Cancer Discov 2014; 4: 1371-1373. http://dx.doi. org/10.1158/2159-8290.CD-14-1228

[48] VAUGHN AE, DESHMUKH M Glucose metabolism inhibits apoptosis in neurons and cancer cells by redox inactivation of cytochrome c. Nature cell biology 2008; 10: 1477-1483. http:// dx.doi.org/10.1038/ncb1807

[49] ZHANG J, WANG G, MAO Q, LI S, XIONG W et al. Glutamate dehydrogenase $(\mathrm{GDH})$ regulates bioenergetics and redox homeostasis in human glioma. Oncotarget 2016; [Epub ahead of print] http://dx.doi.org/10.18632/oncotarget.7657

[50] ZHANG L, WANG K, LEI Y, LI Q, NICE EC et al. Redox signaling: Potential arbitrator of autophagy and apoptosis in therapeutic response. Ree Radic Biol Med 2015; 89: 452-465. http://dx.doi.org/10.1016/j.freeradbiomed.2015.08.030

[51] NOGUEIRA V, PARK Y, CHEN CC, XU PZ, CHEN ML et al. Akt determines replicative senescence and oxidative or oncogenic premature senescence and sensitizes cells to oxidative apoptosis. Cancer Cell 2008; 14: 458-470. http://dx.doi. org/10.1016/j.ccr.2008.11.003

[52] WALENTA S, MUELLER-KLIESER WF Lactate: mirror and motor of tumor malignancy. Semin Radiat Oncol 2004; 14: 267-274. http://dx.doi.org/10.1016/j. semradonc.2004.04.004

[53] DHUP S, DADHICH RK, PORPORATO PE, SONVEAUX P Multiple biological activities of lactic acid in cancer: influences on tumor growth, angiogenesis and metastasis. Curr Pharm Des 2012; 18: 1319-1330. http://dx.doi. org/10.2174/138161212799504902

[54] WALENTA S, WETTERLING M, LEHRKE M, SCHWICKERT G, SUNDFOR K ET AL. High lactate levels predict likelihood of metastases, tumor recurrence, and restricted patient survival in human cervical cancers. Cancer Res 2000; 60: 916-921.

[55] DE KEIJZER MH, BRANDTS RW, BRANS PGW Evaluation of a biosensor for the measurement of lactate in whole blood. Clin Biochem 1999; 32: 109-112 http://dx.doi.org/10.1016/ $\underline{\mathrm{S} 0009-9120(98) 00105-2}$

[56] BONEN A The expression of lactate transporters (MCT1 and MCT4) in heart and muscle. Eur J Appl Physiol 2001; 86: 6-11. http://dx.doi.org/10.1007/s004210100516

[57] BOUZIER-SORE AK, VOISIN P, CANIONI P, MAGISTRETTI PJ, PELLERIN L Lactate is a preferential oxidative energy substrate over glucose for neurons in culture. J Cereb 
Blood Flow Metab 2003; 23: 1298-1306. http://dx.doi. org/10.1097/01.WCB.0000091761.61714.25

[58] PELLERIN L, MAGISTRETTI PJ Neuroenergetics: calling upon astrocytes to satisfy hungry neurons. Neuroscientist 2004; 10: 53-62. http://dx.doi.org/10.1177/1073858403260159

[59] SONVEAUX P, VEGRAN F, SCHROEDER T, WERGIN M, VERRAX J et al. Targeting lactate-fueled respiration selectively kills hypoxic tumor cells in mice. J Clin Invest 2008; 118: 3930-3942. http://dx.doi.org/10.1172/jci36843

[60] CHANDEL NS Mitochondria as signaling organelles. BMC Biol 2014; 12:34. http://dx.doi.org/10.1186/1741-7007-12$\underline{34}$

[61] GIANNONI E, BURICCHI F, RAUGEI G, RAMPONI G, CHIARUGI P Intracellular reactive oxygen species activate Src tyrosine kinase during cell adhesion and anchoragedependent cell growth. Mol Cell Biol 2005; 25: 6391-6403. http://dx.doi.org/10.1128/MCB.25.15.6391-6403.2005

[62] SULLIVAN LB, CHANDEL NS Mitochondrial reactive oxygen species and cancer. Cancer Metab 2014; 2:17. http:// dx.doi.org/10.1186/2049-3002-2-17

[63] SZATROWSKI TP, NATHAN CF Production of large amounts of hydrogen peroxide by human tumor cells. Cancer Res 1991; 51: 794-798.

[64] CAIRNS RA, HARRIS IS, MAK TW Regulation of cancer cell metabolism. Nat Rev Cancer 2011; 11: 85-95. http://dx.doi. org/10.1038/nrc2981

[65] LEE G, WON HS, LEE YM, CHOI JW, OH TI et al. Oxidative Dimerization of PHD2 is Responsible for its Inactivation and Contributes to Metabolic Reprogramming via HIF-1a Activation. Sci Rep 2016; 6: 18928. http://dx.doi.org/10.1038/ $\underline{\text { srep } 18928}$

[66] MOVAFAGH S, CROOK S, VO K Regulation of hypoxiainducible factor-1a by reactive oxygen species: new developments in an old debate. J Cell Biochem 2015; 116:696-703. http://dx.doi.org/10.1002/jcb.25074

[67] MASOUD GN, LI W HIF-1 $\alpha$ pathway: role, regulation and intervention for cancer therapy. Acta Pharm Sin B 2015; 5: 378-389. http://dx.doi.org/10.1016/j.apsb.2015.05.007

[68] MURPHY MP Modulating mitochondrial intracellular location as a redox signal. Sci Signal 2012; 5:pe39. http://dx.doi. org/10.1126/scisignal.2003386

[69] MCCLAIN DA Hexosamines as mediators of nutrient sensing and regulation in diabetes. J Diabetes Complicat 2002; 16: 72-80. http://dx.doi.org/10.1016/S1056-8727(01)00188-X

[70] VASSEUR S, MANIE SN ER stress and hexosamine pathway during tumourigenesis: A pas de deux? Semin Cancer Biol 2015; 33: 34-39. http://dx.doi.org/10.1016/j.semcancer.2015.04.001

[71] GAGLIO D, METALLO CM, GAMEIRO PA, HILLER K, DANNA LS ET AL. Oncogenic K-Ras decouples glucose and glutamine metabolism to support cancer cell growth."Molecular Systems Biology; 2011 7: 523. http://dx.doi.org/10.1038/ msb.2011.56

[72] GUILLAUMOND F, LECA J, OLIVARES O, LAVAUT $\mathrm{MN}, \mathrm{VIDAL} \mathrm{N}$ et al. Strengthened glycolysis under hypoxia supports tumor symbiosis and hexosamine biosynthesis in pancreatic adenocarcinoma. PNAS; 2013 110: 3919-3924. http://dx.doi.org/10.1073/pnas.1219555110
[73] MA Z, VOSSELLER K O-GlcNAc in cancer biology. Amino Acids 2013; 45: 719-733. http://dx.doi.org/10.1007/s00726$\underline{013-1543-8}$

[74] RIGANTI C, GAZZANO E, POLIMENI M, ALDIERI E, GHIGO D The pentose phosphate pathway: an antioxidant defense and a crossroad in tumor cell fate. Free Radical Bio Med 2012; 53: 421-436. http://dx.doi.org/10.1016/j. freeradbiomed.2012.05.006

[75] PATRA KC, HAY N The pentose phosphate pathway and cancer. Trends Biochem Sci 2014; 39: 347-354. http://dx.doi. org/10.1016/j.tibs.2014.06.005

[76] STANTON RC, SEIFTER JL, BOXER DC, ZIMMERMAN E, CANTLEY LC Rapid release of bound glucose-6-phosphate dehydrogenase by growth factors. Correlation with increased enzymatic activity. J Biol Chem 1991; 266: 12442-12448.

[77] TIAN WN, PIGNATARE JN, STANTON RC Signal transduction proteins that associate with the platelet-derived growth factor (PDGF) receptor mediate the PDGF-induced release of glucose-6-phosphate dehydrogenase from permeabilized cells. J Biol Chem 1994; 269: 14798-14805.

[78] PAN S, WORLD CJ, KOVACS CJ, BERK BC Glucose 6-phosphate dehydrogenase is regulated through c-Src-mediated tyrosine phosphorylation in endothelial cells. Arterioscl Throm Vas 2009; 29: 895-901. http://dx.doi.org/10.1161/ ATVBAHA.109.184812

[79] LANGBEIN S, ZERILLI M, ZUR HAUSEN A, STAIGER W, RENSCH-BOSCHERT $\mathrm{K}$ et al. Expression of transketolase TKTL1 predicts colon and urothelial cancer patient survival: Warburg effect reinterpreted. Brit J Cancer 2006; 94: 578-585. http://dx.doi.org/10.1038/sj.bjc.6602962

[80] HEINRICH PC, MORRIS HP, WEBER G Behavior of transaldolase (EC 2.2.1.2) and transketolase (EC 2.2.1.1) Activities in normal, neoplastic, differentiating, and regenerating liver. Cancer Res 1976; 36: 3189-3197.

[81] BOROS LG, PUIGJANER J, CASCANTE M, LEE WN, BRANDES JL et al. Oxythiamine and dehydroepiandrosterone inhibit the nonoxidative synthesis of ribose and tumor cell proliferation. Cancer Res 1997; 57: 4242-4248.

[82] MAZUREK S, BOSCHEK CB, HUGO F, EIGENBRODT E Pyruvate kinase type M2 and its role in tumor growth and spreading. Semin Cancer Biol 2005; 15: 300-308. http://dx.doi. org/10.1016/j.semcancer.2005.04.009

[83] CHRISTOFK HR, VANDER HEIDEN MG, HARRIS MH, RAMANATHAN A, GERSZTEN RE et al. The M2 splice isoform of pyruvate kinase is important for cancer metabolism and tumour growth. Nature 2008; 452: 230-233. http://dx.doi. org/10.1038/nature06734

[84] SUN Q, CHEN X, MA J, PENG H, WANG F et al. Mammalian target of rapamycin up-regulation of pyruvate kinase isoenzyme type M2 is critical for aerobic glycolysis and tumor growth. PNAS 2011; 108: 4129-4134. http://dx.doi. org/10.1073/pnas.1014769108

[85] PAYEN VL, PORPORATO PE, BASELET B, SONVEAUX P Metabolic changes associated with tumor metastasis, part 1 : tumor $\mathrm{pH}$, glycolysis and the pentose phosphate pathway." Cell Mol Life Sci 2016; 73: 1333-1348. http://dx.doi.org/10.1007/ s00018-015-2098-5 
[86] JIANG P, DU W, WU M Regulation of the pentose phosphate pathway in cancer. Protein Cell. 2014; 5:592-602. http:// dx.doi.org/10.1007/s13238-014-0082-8

[87] KOVACEVIC Z, MCGIVAN JD. Mitochondrial metabolism of glutamine and glutamate and its physiological significance. Physiol Rev 1983; 63:547-605.

[88] NELSON JA, FALK RE The efficacy of phloridzin and phloretin on tumor cell growth. Anticancer Res 1993; 13: 2287-2292.

[89] DE LENA M, LORUSSO V, LATORRE A, FANIZZA G, GARGANO G et al. Paclitaxel, cisplatin and lonidamine in advanced ovarian cancer. A phase II study. Eur J Cancer 2001; 37: 364-368. http://dx.doi.org/10.1016/S0959-8049(00)00400-7

[90] DI COSIMO S, FERRETTI G, PAPALDO P, CARLINI P, FABI A et al. Lonidamine: efficacy and safety in clinical trials for the treatment of solid tumors. Drugs Today (Barc) 2003; 39: 157-174. http://dx.doi.org/10.1358/dot.2003.39.3.799451

[91] TENNANT DA, DURAN RV, GOTTLIEB E Targeting metabolic transformation for cancer therapy. Nat Rev Cancer 2010; 10: 267-277. http://dx.doi.org/10.1038/nrc2817

[92] FANTIN VR, ST-PIERRE J, LEDER P Attenuation of LDH-A expression uncovers a link between glycolysis, mitochondrial physiology, and tumor maintenance. Cancer Cell 2006; 9: 425-434. http://dx.doi.org/10.1016/j.ccr.2006.04.023

[93] SUN RC, FADIA M, DAHLSTROM JE, PARISH CR, BOARD PG et al. Reversal of the glycolytic phenotype by dichloroacetate inhibits metastatic breast cancer cell growth in vitro and in vivo. Breast Cancer Res Treat 2009; 120: 253-260. http:// dx.doi.org/10.1007/s10549-009-0435-9

[94] WANG JB, ERICKSON JW, FUJI R, RAMACHANDRAN S, GAO P, et al. Targeting mitochondrial glutaminase activity inhibits oncogenic transformation. Cancer Cell 2010; 18, 207-219. http://dx.doi.org/10.1016/j.ccr.2010.08.009

[95] LE A, LANE AN, HAMAKER M, BOSE S, GOUW A et al. Glucose-independent glutamine metabolism via TCA cycling for proliferation and survival in B cells. Cell Metab 2012; 15, 110-121. http://dx.doi.org/10.1016/j.cmet.2011.12.009

[96] QING G, LI B, VU A, SKULI N, WALTON ZE et al. ATF4 regulates MYC-mediated neuroblastoma cell death upon glutamine deprivation. Cancer Cell 2012; 22: 631-644. http:// dx.doi.org/10.1016/j.ccr.2012.09.021

[97] THORNBURG JM, NELSON KK, CLEM BF, LANE AN, ARUMUGAM $S$ et al. Targeting aspartate aminotransferase in breast cancer. Breast Cancer Res 2008; 10: R84. http://dx.doi. org/10.1186/bcr2154

[98] YANG C, SUDDERTH J, DANG T, BACHOO RG, MCDONALD JG et al. Glioblastoma cells require glutamate dehydrogenase to survive impairments of glucose metabolism or Akt signaling. Cancer Res 2009; 69: 7986-7993. http:// dx.doi.org/10.1158/0008-5472.CAN-09-2266

[99] BAILEY CJ, TURNER RC Metformin. N Engl J Med 1996; 334: 574-579. http://dx.doi.org/10.1056/ NEJM199602293340906

[100] POLLAK, M. The insulin and insulin-like growth factor receptor family in neoplasia: an update. Nat Rev Cancer 2012; 12 : 159-169. http://dx.doi.org/10.1038/nrc3215

[101] POLLAK M. Overcoming drug development bottlenecks with repurposing: repurposing biguanides to target energy metabolism for cancer treatment. Nat Med 2014; 20, 591-593. http://dx.doi.org/10.1038/nm.3596

[102] ZHANG X, FRYKNAS M, HERNLUND E, FAYAD W, DE MILITO A et al. Induction of mitochondrial dysfunction as a strategy for targeting tumour cells in metabolically compromised microenvironments. Nat Commun 2014; 5, 3295. http://dx.doi.org/10.1038/ncomms4295

[103] CHAE YC, CAINO MC, LISANTI S, GHOSH JC, DOHI T et al. Control of tumor bioenergetics and survival stress signaling by mitochondrial HSP90s. Cancer Cell 2012; 22, 331-344. http://dx.doi.org/10.1016/j.ccr.2012.07.015 